\title{
ACIDENTES DE TRABALHO COM INSTRUMENTOS PERFUROCORTANTES ENTRE OS TRABALHADORES DE ENFERMAGEM 1
}

\author{
ACCIDENTS WITH SHARP INSTRUMENTS AMONG NURSING WORKERS
}

\section{ACCIDENTES DE TRABAJO CON INSTRUMENTOS PERFORO CORTANTES ENTRE ENFERMEROS TRABAJADORES}

Leila Maria Mansano Sarquis* Vanda Elisa Andres Felli**

Sarquis LMM, Felli VEA. Acidentes de trabalho com instrumentos perfurocortantes entre os trabalhadores de enfermagem. Rev Esc Enferm USP 2002; 36(3): 222-30.

\begin{abstract}
RESUMO
O presente estudo analisou os acidentes de trabalho ocorridos com trabalhadores de enfermagem, de um hospital público, provocados por instrumentos perfurocortantes. A instituição campo de estudo foi um hospital público do interior de São Paulo. A população foi composta por 787 trabalhadores de enfermagem. Na coleta de dados foram usados dois instrumentos: o primeiro foi o questionário que se destinou ao levantamento dos dados referentes aos acidentes de trabalho ocorridos no ano de 1996; o segundo foi a entrevista realizada com estes trabalhadores que sofreram acidentes com instrumentos perfurocortantes. Os resultados encontrados mostram a significativa freqüencia desse tipo de acidente entre os auxiliares de enfermagem. A interação do trabalhadores de enfermagem com instrumentos perfurocortantes, indica a grande exposição aos riscos biológicos e às graves doenças.
\end{abstract}

PALAVRAS-CHAVE: Enfermagem. Saúde ocupacional. Acidentes de trabalho.

\begin{abstract}
The present study analyzed the accidents happened at work with the nursing staff of a public hospital, provoked by sharp instruments. All the nursing staff composed the study population. In the collection of data two instruments were used: a questionnaire designed to collect data referring to all working accidents that happened in the year of 1996; the second was an interview accomplished with these workers that suffered accidents with sharp instruments. The results showed that the nursing staff health is under risk with sharp instruments is involved in the accidents. For these accidents, the greater risk coefficients were for nursing auxiliary. High subnotification was verified for those accidents. The relative results of the interaction of the nursing staff working with sharp instruments indicate the great exposure to the biological risks and the serious diseases.
\end{abstract}

KEYWORDS: Nursing. Occupational health. Accidents, occupational.

\section{RESUMEN}

El presente estudio analizó los accidentes de trabajo ocurridos con enfermeros trabajadores, de un hospital público, ocasionados por instrumentos perforo cortantes. La institución campo de estudio fue un hospital público del interior de San Pablo. La población fue compuesta por 787 enfermeros trabajadores. En la coleta de datos fueran usados dos instrumentos: el primer fue un cuestionario que se destinó al examen de datos referentes a los accidentes de trabajo ocurridos en el ano de 1996; el segundo fue una cita con estos trabajadores que sufrieron accidentes con instrumentos perforo cortantes. Los resultados mostran la significativa frecuencia de ese tipo de accidente entre los auxiliares de enfermero. La interacción de los enfermeros trabajadores con instrumentos perforo cortantes indica la grande exposición a los riesgos biológicos y a las graves enfermedades.

PALABRAS-CLAVE: Oficio de enfermero o practicante. Salud ocupacional. Accidentes de trabajo.

\footnotetext{
1 Elaborado a partir da dissertação de Mestrado "Acidentes de trabalho com instrumentos perfurocortantes: ocorrência entre ostrabalhadores de enfermagem", defendida em novembro de 1999, na Escola de Enfermagem da USP

** Enfermeira. Prof. Ms. da Universidade Tuiuti do Paraná - Curso de Graduação em Enfermagem, Disciplina Administração em Enfermagem.

*** Enfermeira. Prof ${ }^{a}$. Dra . do Departamento de Orientação Profissional da Escola de Enfermagem da USP.
} 


\section{INTRODUÇÃO}

Nos dias atuais, os ferimentos perfurocortantes que acometem os trabalhadores de enfermagem representam um grave problema nas instituições de saúde, tanto pela freqüência com que ocorrem, como pela grave repercussão que representam sobre a saúde desses trabalhadores.

Essa preocupação não é recente pois já em 1981 representantes da Organização Mundial de SaúdeOMS, reunidos em Haya, reconheceram não dispor de estatísticas nacionais e internacionais sobre acidentes e lesões que afetam os profissionais de saúde e dentre eles os trabalhadores de enfermagem (1)

Assim, mesmo com as publicações e pesquisas que vêm sendo desenvolvidas, o conhecimento ainda é insuficiente para apreender a complexidade dessa problemática, que envolve os trabalhadores de enfermagem. (2)

O trabalho de enfermagem na instituição hospitalar caracteriza-se pelo cuidado nas 24 horas do dia, permitindo a continuidade da assistência aos pacientes. Nesse cuidado aos pacientes, os trabalhadores de enfermagem utilizam instrumentos de trabalho como: agulhas, lâminas de bisturi, tesouras, pinças, materiais de vidro e muitos outros instrumentos que são perfurantes e cortantes. Cuidam muitas vezes de pacientes agressivos, agitados, ansiosos ou em estado crítico, onde encontram dificuldade de realizar os procedimentos com segurança. Além disso, o trabalho de enfermagem nesta instituição, caracteristicamente, tem um ritmo acelerado, é realizado em pé, com muitas caminhadas e sob a supervisão estrita; é normatizado, rotinizado e fragmentado.(3)

Nesse contexto, apreendemos que é grande o número de trabalhadores de enfermagem expostos mais continuamente ao risco de acidentes com ferimentos perfurocortantes.

Diante dessa problemática, interessa-nos aprofundar a reflexão e a geração de conhecimentos a respeito dos acidentes com materiais perfurocortantes, a que estão expostos os trabalhadores de enfermagem de um hospital.

Assim, passamos a abordar os fundamentos teóricos que explicam a relação trabalho de enfermagem e a saúde dos trabalhadores, que se manifesta pelos acidentes com perfurocortantes.

O estudo da relação saúde trabalho cunhado na teoria da determinação social do processo saúdedoença, construído por Laurell; Noriega (4), foi aplicado ao trabalho de enfermagem por Silva(2). Nessa construção foram evidenciados os conceitos de carga e desgaste submetidos ao processo de valorização que se caracteriza no processo de trabalho.
Os "riscos ocupacionais são agentes existentes no ambiente de trabalho, capazes de causar doença"(4) Assim, a noção de risco pressupõe elementos isolados entre si da dinâmica global do processo de trabalho. Portanto, para entendermos o processo saúde-doença subordinado ao trabalho, faz-se necessário construir outra categoria de análise que consiste na carga de trabalho. A categoria carga de trabalho é concebida pelos "elementos do processo de trabalho, que interatuam entre si e com o corpo do trabalhador, gerando os processos de adaptação que se traduzem em desgaste". Ou seja, o trabalhador ao transformar o objeto de trabalho, utilizando meios e instrumentos, em determinadas formas de organização e divisão de trabalho, expõe-se às cargas de trabalho.

As cargas físicas, químicas, biológicas $e$ mecânicas possuem uma materialidade externa ao corpo podem ser quantificadas, das cargas fisiológicas e psíquicas, que se caracterizam por terem materialidade interna ${ }^{4}$. Isto é, adquirem materialidade no corpo humano, ao expressarem-se. em transformações nos seus processos internos. Fundamentada nessa classificação (4 , Silva(2) faz uma aproximação com o trabalho de enfermagem, recompondo as cargas de trabalho a que estão expostos os trabalhadores.

Assim, a exposição dos trabalhadores de enfermagem às cargas físicas são exemplificadas pelos ruídos internos e externos ao ambiente de trabalho, temperaturas externas ao ambiente de trabalho, radiações ionizantes e não ionizantes e pelos efeitos da eletricidade.

As cargas quimicas abrangem todas as substâncias químicas que estão presentes no processo de trabalho de enfermagem, como as utilizadas no processo de esterilização e desinfecção de materiais, em anestesias e nos tratamentos medicamentosos dos pacientes.

Nas cargas biológicas estão incluídos os microrganismos patogênicos, que podem causar danos à saúde do trabalhador, provenientes do contato com pacientes portadores de doenças infecciosas, infectocontagiosas e parasitárias e da manipulação de materiais contaminados.

As cargas mecânicas podem ser desencadeadas pela ruptura instantânea do corpo em forma de contusões; feridas; fraturas; ferimentos cortantes, perfurantes, entre outros. A exposição às cargas mecânicas, geralmente caracteriza o acidente de trabalho.

As cargas de materialidade interna podem ser classificadas em cargas fisiológicas e psíquicas, conforme segue:

As cargas, fisiológicas caracterizam-se em processos corporais transformados, pelo esforço físico pesado, que desencadeará um consumo calórico 
aumentado com gasto e hipertrofia de tecidos, e pela alternância de turnos, causando ruptura dos ritmos fisiológicos básicos.

As cargas psiquicas são exemplificadas pela exposição à atenção permanente no trabalho, à supervisão com pressão, à consciência da periculosidade do trabalho, aos altos ritmos de trabalho, à repetitividade, à monotonia e à falta de criatividade.

Porém, é na interação entre as cargas dos diferentes grupos que se começa a vislumbrar plenamente a necessidade de analisá-las de uma forma global, articuladas ao processo de trabalho (4).

Os trabalhadores de enfermagem estão expostos a uma diversidade e simultaneidade de cargas de trabalho que geram processos de desgaste que, em seu estudo, foram apreendidos pela morbidade referida pelos trabalhadores, morbidade registrada nos exames médicos periódicos e pelos acidentes de trabalho (4).

No ambiente hospitalar, os avanços tecnológicos relativos aos equipamentos, materiais e procedimentos e o grau de complexidade das atividades realizadas pelos trabalhadores de enfermagem, os expõem a vários tipos de riscos que se expressam por diferentes problemas de saúde.

No Brasil, os estudos que enfocam a relação saúde-trabalho de enfermagem nas instituições hospitalares, começaram a ser realizados na década de 70 e foram incrementados a partir da década de 80 . Estes estudos demonstram que a saúde do trabalhador de enfermagem é comprometida. Este comprometimento, em parte, pode ser detectado através da elevada incidência de acidentes de trabalho e doenças profissionais (5)

Alguns destes estudos, desenvolvidos em nosso país, na última década, permitem situar e contextualisar a problemática do processo saúdedoença vivenciada pelos trabalhadores de enfermagem.(5-16) Nessas investigações, os autores abordam a saúde do trabalhador e a sua relação com o trabalho.

Nestes estudos apreendemos a preocupação com duas formas de expressão do processo de desgaste vivenciado pelos trabalhadores de enfermagem: os acidentes de trabalho e as doenças. A forma mais abrupta de desgaste que é o acidente de trabalho, tem merecida atenção dos estudiosos.

Dentre os vários tipos de acidentes, os perfurocortantes são, não só, os mais freqüentes, como também os mais graves, por possibilitarem o desenvolvimento de doenças letais para os trabalhadores.

O interesse pela questão do acidente de trabalho com instrumentos perfurocortantes tornou-se mais evidente, quando a AIDS (Síndrome da Imunodeficiência Adquirida) se expandiu, tornando-se uma pandemia. Alguns profissionais de saúde foram contaminados pelo vírus da AIDS, o HIV (vírus da imunodeficiência humana), no trabalho. Estes casos foram confirmados e descritos pelo Centers for Disease Control - CDC Atlanta, somando 52 casos de soroconversão após exposição ocupacional.(17)

A transmissão do HIV em profissionais de saúde foi associada, principalmente, aos acidentes com instrumentos perfurocortantes. ${ }^{(18)}$

A importância desses acidentes extrapola a ocorrência da simples lesão e adquire maior gravidade quando os instrumentos estão contaminados com sangue e secreções. Nessa situação, é reconhecida a possibilidade de transmissão de microrganismos patogênicos, capazes de gerar outros processos de desgaste, geralmente mais graves que o ferimento em si, dentre eles a hepatite e a AIDS. (2) Outros estudos realizados em nosso país também confirmam a gravidade desta problemática constatando a presença de fatores de riscos que estão expostos os trabalhadores de enfermagem. ${ }^{(9-20)}$

$\mathrm{O}$ risco médio de adquirir o $\mathrm{HIV}$, segundo o CDC, que é adotado pelo Ministério da Saúde do nosso País, para todos os tipos de exposição percutânea é de $0,3 \%$ e pode aumentar, devido à carga viral, se o ferimento for profundo, se houver sangue visivel no instrumento causador do ferimento, se o instrumento foi previamente colocado em veia profunda ou artéria de paciente e se o paciente-fonte tenha falecido no período de 60 dias após o acidente.(22)

Em relação à infecção pelo vírus da hepatite BHBV, Bulhões (21) refere que $10 \%$ dos casos podem evoluir para uma forma fulminante da hepatite ou para uma forma crônica, como o carcinoma de figado e cirrose hepática. $\mathrm{O}$ risco de transmissão ocupacional da hepatite B após o acidente percutâneo é de $30 \%$.(22) Outros autores ainda afirmam que vários estudos sobre a hepatite $B$ têm demonstrado que a prevalência deste virus é maior entre profissionais da saúde, quando comparados à população geral. (23)

Em nosso país, os estudos também mostram porcentagem diferenciadas e preocupantes. Silva (6) identificou a freqüência de $32 \%$ de afastamentos em acidentes de trabalho por lacerações e feridas, onde estão inclusos os ferimentos perfurocortantes. Em outro estudo e em outra instituição, a mesma autora (2) referiu que, do total de danos decorrentes dos acidentes de trabalho, aproximadamente 55\% foram ferimentos perfurocortantes. Identificou que os trabalhadores mais expostos a esse tipo de acidentes, são os auxiliares de enfermagem, relacionando essa freqüência às especificidades do processo de trabalho realizado nas unidades.

Foi analisado a ocorrência de acidentes e os fatores de riscos entre os trabalhadores de 
enfermagem; onde foi encontrado em seus estudos que $41 \%$ dos acidentes estavam relacionados especificamente com objetos perfurocortantes, referindo um subregistro de 46,3\%.(12) Em outra pesquisa recente realizadatambém confirmam a grande subnotificação destes trabalhadores e afirmam ter encontrado um percentual de $69 \%$ de acidentes nesta classe trabalhadora. (19) Estes achados também confirmam a grande exposição destes trabalhadores na ocorrência de acidente com material biológico.(20)

Os acidentes com perfurocortantes representam uma preocupação em diferentes realidades, como se pode verificar em vários estudos.

Em Nova York (24) os pesquisadores encontraram que $50 \%$ dos acidentes com instrumentos perfurocortantes aconteceram pelo fato destes objetos estarem em local impróprio de descarte, sem condições de segurança. Já outro pesquisador (25) em Nevada, encontrou que, dos acidentes estudados, 35\% estavam relacionadas aos perfurocortantes e que a equipe de enfermagem fica exposta a adquirir doenças decorrentes desses acidentes em até $58 \%$.

Ainda, nas instituições hospitalares de outros países como Austrália e Arábia Saudita e países europeus encontram-se freqüências de acidentes com perfurocortantes entre os trabalhadores de enfermagem muito altas e variadas. Vários autores referem freqüências que variam de $50 \%$ a $90 \%$ em trabalhadores de enfermagem. (24,26-29)

Embora os estudos, tanto nacionais como internacionais referem freqüências muito altas para esse tipo de acidentes, acrescenta-se ainda a sua subnotificação pelos trabalhadores.

A prevenção de acidentes de trabalho é a medida que pode, mais significativamente, diminuir essa exposição ocupacional aos riscos biológicos e mecânicos inerentes ao trabalho. Os trabalhadores de enfermagem ficam mais expostos a esses riscos por trabalharem com objetos perfurocortantes, que permitem maior exposição a sangue e fluidos corpóreos.

Apesar da possibilidade de prevenção desses acidentes pelo uso das precauções padrão, além do uso de outros dispositivos de segurança, como sistemas sem o uso de agulhas para a administração de medicamento em equipos intravasculares, sistemas de agulhas que retraem após o uso mas nem sempre estas recomendações são facilmente praticadas ou adotadas, pois ainda se observa um alto índice destes acidentes com sérias conseqüências. Para que os acidentes com perfurocortantes sejam evitados, há a necessidade de, não só, promover periodicamente treinamento em serviço com o objetivo de diminuir a sua freqüência, mas também permitir que os trabalhadores consigam decodificar a organização de trabalho em que estão inseridos, podendo trabalhar com segurança e encontrando soluções para sua prática diária.
Assim, a pouca atenção dispensada a essa problemática na prática, a grande freqüência de acidentes com perfurocortantes; a sua significativa não notificação desses acidentes; a necessidade de preveni-los, devido às graves conseqüências que atingem a um grande número de trabalhadores expostos a esses acidentes e a necessidade de aprofundar conhecimento sobre o tema, justificam a realização deste estudo que tem por objetivo:

\section{OBJETIVO}

Analisar os acidentes de trabalho ocorridos com trabalhadores de enfermagem, de um hospital público e geral, provocados por instrumentos perfurocortantes.

\section{TRAJETÓRIA METODOLÓGICA}

O estudo caracterizou-se como exploratório, assumindo a forma de um estudo de caso, uma vez que objetiva tornar mais explícita a ocorrência do problema de acidente de trabalho com instrumentos perfurocortantes em uma instituição hospitalar especifica.

A instituição campo de estudo foi um hospital público e universitário do interior do Estado de São Paulo.

A população foi composta por todos os trabalhadores de enfermagem do referido hospital, que estavam trabalhando no periodo da coleta, totalizando 787 trabalhadores. Deste total 67 são enfermeiros, 475 auxiliares de enfermagem e 245 atendentes de enfermagem. Na categoria auxiliar de enfermagem, foram considerados os técnicos de enfermagem existentes em reduzido número, uma vez que as atividades desenvolvidas eram as mesmas. Responderam ao questionário 618 trabalhadores.

O dado considerado de interesse para o estudo foi o acidente de trabalho com instrumento perfurocortante, ocorrido no período compreendido entre 01 de janeiro e 31 de dezembro de 1996. Para a coleta de dados foram utilizados dois instrumentos.

O primeiro, foi o questionário que se destinou ao levantamento dos dados referentes a todos os acidentes de trabalhos ocorridos com trabalhadores de enfermagem no ano de 1996, em relação à descrição do acidente ou dano provocado, do objeto causador e a comunicação do acidente, além dos dados pessoais e profissionais dos trabalhadores.

O segundo, foi a entrevista utilizada apenas com os trabalhadores de enfermagem que sofreram acidentes de trabalho com instrumento perfurocortante no ano de 1996, cujos dados investigados incluíram: identificação do trabalhador 
e os dados sobre o acidente, como notificação, providencias tomadas no uso do equipamento de proteção individual e sugestões de prevenção para diminuição dos acidentes.

O estudo foi anteriormente aprovado pelo Comitê de Ética em Pesquisa da Instituição, sendo adotadas as normas da Resolução 196/96.

\section{RESULTADOS E DISCUSSÃO}

Os resultados serão apresentados e discutidos conjuntamente para melhor compreensão.

A TABELA 1 mostra a composição da força de trabalho do hospital e a TABELA 2 a freqüência dos acidentes segundo o sexo.

Tabela 1 - Freqüência dos trabalhadores de enfermagem, segundo os acidentes no trabalho e a categoria profissional, 1996.

\begin{tabular}{|c|c|c|c|c|c|}
\hline \multirow{2}{*}{$\begin{array}{l}\text { Categoria } \\
\text { Profissional }\end{array}$} & \multicolumn{2}{|c|}{$\begin{array}{c}\text { Trabalha- } \\
\text { dores }\end{array}$} & \multicolumn{2}{|c|}{$\begin{array}{l}\text { Acidenta- } \\
\text { dos }\end{array}$} & \multirow{2}{*}{$\mathbf{C R}^{*}$} \\
\hline & $\mathbf{N}^{\circ}$ & $\%$ & $\mathbf{N}^{\circ}$ & $\%$ & \\
\hline $\begin{array}{c}\text { Auxiliar de } \\
\text { Enfermagem }\end{array}$ & & 70,60 & 66 & 80,50 & 15,13 \\
\hline $\begin{array}{l}\text { Atendente de } \\
\text { Enfermagem }\end{array}$ & 135 & 21,80 & 12 & 14,60 & 8,88 \\
\hline Enfermeiro & 47 & 7,60 & 4 & 4,90 & 8,51 \\
\hline Total & 618 & 100,0 & 82 & 100,0 & 13,2 \\
\hline
\end{tabular}

${ }^{*} \mathrm{CR}$ - Coeficiente de risco

Tabela 2 - Freqüência dos trabalhadores de enfermagem acidentados, segundo o sexo,1996.

\begin{tabular}{l|cc|cc|c}
\hline \multirow{2}{*}{ Sexo } & \multicolumn{2}{|c|}{$\begin{array}{c}\text { Trabalha- } \\
\text { dores }\end{array}$} & \multicolumn{2}{|c|}{$\begin{array}{c}\text { Acidenta- } \\
\text { dos }\end{array}$} & \multirow{2}{*}{$\mathbf{C R}^{*}$} \\
\cline { 2 - 5 } & $\mathbf{N}^{\circ}$ & $\%$ & $\mathbf{N}^{\circ}$ & $\%$ & \\
\hline Masculino & 120 & 19,41 & 13 & 2,10 & 10,83 \\
Feminino & 498 & 80,59 & 69 & 11,16 & 13,85 \\
\hline Total & 618 & 100,0 & 82 & 13,2 & 100,0 \\
\hline
\end{tabular}

Observamos que a maior parte dos trabalhadores de enfermagem pertence à categoria profissional auxiliar de enfermagem $(70,60 \%)$. Ao compararmos o contingente de trabalhadores acidentados, verificamos que houve variação na freqüência de acidentes, que pode ser analisada pelos coeficientes de risco. Enquanto na categoria auxiliar de enfermagem, encontramos um $\mathrm{CR}=$ 15,13 acidentes/100 auxiliares, nas outras categorias, esse coeficiente foi de 8,88 acidentes/100 para os atendentes de enfermagem e de 8,51 acidentes/100 para os enfermeiros.
Verificamos que na categoria auxiliar de enfermagem o coeficiente de risco de acidentes de trabalho foi quase o dobro das demais. Isso parece ser explicado pelas atividades que realizam junto aos pacientes, administrando medicamentos e assistindo diretamente, bem como realizando procedimentos de emergência. Essas atividades colocam o auxiliar de enfermagem em exposição contínua ao risco de acidente, conforme mostra a TABELA 1.

Em estudos realizados os achados mostram que os acidentes com instrumentos perfurocortantes acontecem mais entre os auxiliares de enfermagem, o que vem corroborar com os dados obtidos na presente investigação. ${ }^{30,31)}$

A composição da força de trabalho de enfermagem da instituição conforme encontramos na TABELA 2, é predominantemente feminina $(80,59 \%)$.

O CR dos trabalhadores acidentados é maior para a população feminina, com 13,85 acidentes $/ 100$ trabalhadoras e menor para a população masculina (10,83 acidentes / 100 trabalhadores).

A avaliação epidemiológica sobre acidente de trabalho entre os trabalhadores de enfermagem investigaram a ocorrência de determinados acidentes, chama a atenção para a iminência do risco a que estão expostas as trabalhadoras, para a qual também encontraram alta porcentagem de acidentes. $(28,30,33)$ Este assunto também foi estudado recentemente.(34)

$\mathrm{O}$ maior $\mathrm{CR}$ de acidente entre as mulheres parece estar relacionado ao papel que a mulher assume culturalmente na nossa sociedade, onde também cuida da casa, dos filhos e, muitas vezes, também tem mais de um emprego.

Helman $^{(35)}$ refere que, embora a. maioria dos profissionais de saúde pertençam ao sexo feminino, encontramos essas trabalhadoras desenvolvendo seus trabalhos com salários não tão elevados, o que permite inferir que o trabalho desenvolvido soma-se a outras atividades. Isso parece significar maior cansaço e maior número de acidentes como expressão desse desgaste. Um outro estudo que contribuiu com a caracterização do pessoal de enfermagem objetivou caraterizar o pessoal de enfermagem que atua na assistência na América Latina. Encontrou a predominância do gênero feminino, nas categorias menos qualificadas.(36)

Assim, esses estudos confirmam a predominância do sexo feminino na ocorrência de acidentes entre os trabalhadores de enfermagem.

Analisando as atividades que os trabalhadores de enfermagem estavam desenvolvendo quando acidentaram-se, encontramos os seguintes objetos causadores desses acidentes, como podemos verificar na TABELA 3: 
Tabela 3 - Distribuição do acidente de trabalho segundo a causa ou o objeto causador do acidente, 1996.

\begin{tabular}{|l|c|c|}
\hline Causa/Objeto Causador & $\mathbf{N}^{\circ}$ & $\mathbf{\%}$ \\
\hline Instrumento perfurocortante & 44 & 53,70 \\
Carregamento de peso excessivo & 8 & 9,80 \\
Queda ao solo (chão liso, degraus) & 6 & 7,30 \\
Contato com fluídos corpóreos & 5 & 6,10 \\
Condições inseguras de serviço & 5 & 6,10 \\
Contato com produtos químicos & 4 & 3,90 \\
Impacto por queda de objeto & 3 & 3,70 \\
Contato com objeto quente & 3 & 1,20 \\
Queda de n[ivel (buracos) & 1 & 1,20 \\
Inalação de produto químico (tinta) & 1 & 1,20 \\
Picada de insetos (abelha) & 1 & 1,20 \\
Acidente tipo (jogo de futebol) & 1 & 100,0 \\
\hline Total & 82 & \\
\hline
\end{tabular}

A predominância do objeto perfurocortante como causa do acidente aparece com um percentual significativo expresso por esses trabalhadores $(53,70 \%)$. Esses dados vem de encontro com a literatura que afirma ser o perfurocortante o objeto

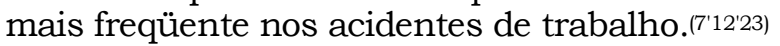

A segunda causa de acidentes de trabalho, está relacionada à manipulação excessiva de peso ao cuidar do paciente, o que, com o decorrer do tempo, desgasta o trabalhador de enfermagem em sua atividade profissional, o que vem de encontro com outro estudo (9) que relatou a ocorrência de cervicodorsolombalgias em profissionais de enfermagem relacionando-as com inadequações de mobiliários e equipamentos utilizados nos procedimentos cotidianos.

Outras situações também são informadas como causa de acidente de trabalho: desnivel no solo, contato com produtos químicos, objetos quentes e outros.

Estes dados vêm corroborar com o estudo realizado por Benatti(12) que também encontrou diferentes acidentes de trabalho ocorridos em ambiente hospitalar. Percebemos então que o trabalhador de enfermagem está exposto aos vários riscos no ambiente de trabalho e compete não só ao trabalhador estar atento aos mesmos, mas também às instituições proporcionarem

Tabela 4 - Distribuição dos acidentes de trabalho, segundo os danos provocados, 1996.

\begin{tabular}{|c|c|c|}
\hline Dano Provocado & $\mathbf{N}^{\circ}$ & $\%$ \\
\hline $\begin{array}{l}\text { Ferimento perfurante } \\
\text { Ferimento cortante sem sutura } \\
\text { Distensão, entorse, luxação, hematoma } \\
\text { Cervicodorsolombalgia } \\
\text { Contaminação biológica } \\
\text { Fratura } \\
\text { Efeito tóxico (produto químico) } \\
\text { Ferimento cortante com sutura } \\
\text { Queimadura de } 1^{\circ} \text { grau } \\
\text { Dermatite de contato (face) } \\
\text { Reação alérgica com edema }\end{array}$ & $\begin{array}{l}34 \\
15 \\
14 \\
8 \\
5 \\
4 \\
3 \\
1 \\
1 \\
1 \\
1\end{array}$ & $\begin{array}{l}39,10 \\
17,20 \\
16,10 \\
9,20 \\
5,70 \\
4,60 \\
3,40 \\
1,10 \\
1,10 \\
1,10 \\
1,10\end{array}$ \\
\hline Total & 87 * & 100,0 \\
\hline
\end{tabular}

*Alguns trabalhadores alegaram dois tipos de danos provocados. medidas de segurança não só aos clientes, mas também aos seus funcionários, onde muitas vezes não encontramos esta realidade na prática.

Encontramos, também na TABELA 3 algumas causas com valores percentuais pequenos $(1,20 \%)$ como queda de nível que estão relacionados aos riscos fisiológicos e químicos, picadas de insetos, inalação de produtos químicos e um acidente tipo relacionado ao jogo de futebol. Outros pesquisadores relatam também ser a enfermagem uma profissão com risco elevado em adquirir doenças no trabalho pela diversificada exposição a que estão submetidos. $(2.12,37)$

$\mathrm{O}$ pesquisador De Luane após 12 meses de estudo encontrou 18.000 novos casos de hepatite B entre os trabalhadores de saúde, confirmando o alto risco biológico a que os trabalhadores estão expostos. Refere que a enfermagem representa $58 \%$ desses trabalhadores e que o instrumento perfurocortante é o objeto causador que mais freqüentemente desencadeou esses acidente.(25)

Em relação ao dano provocado, os ferimentos causados pelos acidentes de trabalho podem ser analisados na TABELA 4. Alguns trabalhadores referiram mais que um tipo de dano provocado pelo acidente, conforme apresentamos a seguir: 
Verificamos que o dano mais freqüente provocado pelo acidente de trabalho foi o ferimento perfurocortante com e sem sutura, somando um total de 50 acidentes, representando um percentual de $57,40 \%$ em relação do total dos acidentes. Outros danos provocados que chamam a atenção estão relacionados à reação alérgica, dermatite de contato e queimaduras, somando um percentual menor $(3,30 \%)$.

Alguns trabalhadores alegaram mais de um dano físico desencadeado no momento do acidente, sendo importante ressaltar que nenhum trabalhador registrou algum tipo de dano moral ou psíquico, embora relatem abalo emocional com o ocorrido.

Podemos constatar que o maior dano está relacionado com o instrumento perfurocortante, contudo, os outros danos provocados nos trabalhadores também desencadearam acidentes. Em relação à faixa etária e categoria dos acidentados com instrumentos perfurocortantes, foram encontrados os seguintes dados apresentados na TABELA 5.

Tabela 5 - Freqüência de trabalhadores que sofreram acidentes com perfurocortantes, segundo categoria e faixa etária, 1996.

\begin{tabular}{|c|c|c|c|c|c|c|c|c|c|c|c|c|}
\hline \multirow[t]{2}{*}{ Faixa Etária } & \multicolumn{3}{|c|}{ Enfermeiro } & \multirow{2}{*}{$\begin{array}{c}\text { Auxiliar } \\
\mathbf{N}^{\circ} \\
\end{array}$} & \multicolumn{2}{|c|}{$\begin{array}{c}\text { de } \\
\text { Enfermage }\end{array}$} & \multicolumn{3}{|c|}{ Atendente } & \multicolumn{3}{|c|}{ Total } \\
\hline & $\mathbf{N}^{\circ}$ & $\%$ & CR & & $\%$ & CR & $\mathbf{N}^{\circ}$ & $\%$ & CR & $\mathbf{N}^{\circ}$ & $\%$ & CR \\
\hline 20 I -30 & - & - & - & 9 & 19,14 & 8,49 & 2 & 4,25 & 1,48 & 11 & 23,40 & 10,37 \\
\hline $30 \mathrm{I}-40$ & - & - & - & 22 & 46,81 & 8,14 & - & - & - & 22 & 46,81 & 8,14 \\
\hline 40 I -50 & 1 & 2,12 & 6,25 & 11 & 23,40 & 5,55 & - & - & - & 12 & 25,53 & 6,06 \\
\hline 50 I -60 & - & - & - & 2 & 4,25 & 4,54 & - & - & - & 2 & 4,25 & 4,54 \\
\hline Total & 1 & 2,12 & 2,12 & 44 & 93,6 & 10,09 & 2 & 4,25 & 1,48 & 47 & 100,0 & 7,60 \\
\hline
\end{tabular}

$\mathrm{Na}$ análise do acidente de trabalho com perfurocortantes segundo a categoria profissional, verificamos que quem mais se acidentou foi o auxiliar de enfermagem, com um $\mathrm{CR}=10,09$ acidentes $/ 100$ trabalhadores e a categoria que menos se acidentou foi o atendente de enfermagem com um $\mathrm{CR}=1,48$. Esses dados sugerem, que tais acidentes são gerados pelas atividades especificas que os trabalhadores desenvolvem, utilizando os instrumentos de trabalho na assistência direta aos pacientes.

Em relação à faixa etária, encontramos que entre os 20 e 30 anos os trabalhadores estão mais expostos aos acidentes com perfurocortantes $(C R=10,37)$, o que possivelmente está relacionado ao desenvolvimento da habilidade do trabalhador no exercício das atividades, pois muitas vezes começa a trabalhar imediatamente após o término da formação, sem ter ainda muita destreza e habilidade técnica. Essa freqüência diferenciase em relação ao restante dos acidentes de trabalho ocorridos na instituição (Sarquis, 1999), em que a faixa etária de maior ocorrência de acidentes localiza-se entre 40 e 50 anos de idade $(C R=15,15)$.

Sarquis (1999) ainda refere que, além do coeficiente de risco para os acidentes com perfurocortantes ser maior, a não notificação destes acidentes foi cerca de $66,00 \%$. Esse dado revela a exposição desses trabalhadores aos processos de desgaste e a inviabilidade de prevenção com quimioprofilaxia, monitoramento e acompanhamento sorológico.

Outros autores também relatam ser o auxiliar de enfermagem a categoria que mais se acidenta. $(30,31)$

Outro dado que podemos observar na tabela é que quanto maior a faixa etária, menor é o coeficiente de risco de acidentes com instrumento perfurocortante, o que reforça o argumento de que o desenvolvimento da habilidade é proporcionada pelo exercício do trabalho.

O tipo de objeto causador que mais desencadeou acidente pode ser encontrada na TABELA 6:

Tabela 6 - Distribuição dos acidentes com instrumento perfurocortante, segundo o tipo de objeto causador, 1996.

\begin{tabular}{l|r|r}
\hline Tipo de Objeto & N & \multicolumn{1}{|c}{$\%$} \\
\hline Perfurante & & \\
Aglha de injeção & 26 & 52,00 \\
Agulha de abocath & 5 & 10,00 \\
Agulha de scalp & 2 & 4,00 \\
Agulha de sutura & 1 & 2,00 \\
Agulha de cateter (uréter) & 1 & 2,00 \\
\hline Subtotal & 35 & 70,00 \\
\hline Cortante & & \\
Vidros(intermediário, pipeta, f. & 10 & 20,00 \\
$\quad$ Aspiração, ampolas). & 3 & \\
Lâmina de bisturi & 1 & 6,00 \\
Lâmina de barbear & 1 & 2,00 \\
Berço aquecido (lateral metálica) & & 2,00 \\
\hline Subtotal & 15 & 30,00 \\
\hline Total & 50 & 100,0 \\
\hline
\end{tabular}

Encontramos que $70 \%$ dos acidentes com perfurocortantes ocorreram com objeto perfurante. Destes, as agulhas de injeção foram os mais freqüentes $(52,00 \%)$. Os objetos cortantes, representados pelos 
objetos de vidros (intermediários pipetas, frascos de aspiração e ampolas), ocorreram com uma porcentagem de $20,00 \%$. Também foram encontrados como a primeira causa de acidente de trabalho entre os trabalhadores de enfermagem o acidente com

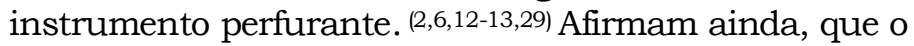
acidente com instrumento perfurante desencadeia mais freqüente contaminação percutânea entre os profissionais de saúde.(39) Outro estudo também afirma que entre todos os acidentes com instrumentos perfurocortantes, a agulha de injeção é o instrumento de trabalho que mais acomete a saúde do trabalhador de enfermagem. (23) Dessa forma, notamos que a grande maioria dos acidentes de trabalho, que comprometem a saúde do trabalhador, está relacionada diretamente com o instrumento de trabalho utilizado para executar a sua função, no seu ambiente de trabalho., bem como com a quantidade de serviço que esse trabalhador desenvolve em sua jornada de trabalho. O ritmo acelerado de trabalho, a dupla jornada desenvolvida por alguns trabalhadores, podem comprometer a saúde desse trabalhador, pois são geradoras de acidentes. Esse aumento do ritmo na produção é, também, gerador de ansiedade e medo no trabalhador, pela possibilidade da ocorrência dos acidentes, pois esse trabalhador ficará mais exposto aos riscos.

\section{CONCLUSÕES}

Os dados analisados neste estudo nos permitem concluir que os ferimentos perfurocortantes que acometem os trabalhadores de enfermagem do referido hospital representam um grave problema. Evidenciou-se em relação a todos os acidentes que:

- A categoria dos auxiliares de enfermagem foi a que mais sofreu acidente de trabalho, com um $C R=15,13$ acidentes.

- A freqüência de acidentes é maior entre as mulheres, o que é demonstrado pelo $\mathrm{CR}=13,85$.

- O objeto causador mais freqüente entre todos os acidentes de trabalho é o instrumento perfurocortante $(53,70 \%)$.

Entre todos os acidentes de trabalho o dano mais freqüente foi o ferimento perfurante $(39,10 \%)$. Evidenciou-se em relação à freqüência dos acidentes com perfurocortantes que:

- A categoria e faixa etária que mais sofreu acidente com perfurocortante foi $\mathrm{o}$ auxiliar de enfermagem com $C R=10,09$.

- A predominância da faixa etária foi entre 20 a 30 anos, observando-se que, quanto maior a faixa etária, menor é o CR para esse acidente para os trabalhadores de enfermagem.
- $70 \%$ desses acidentes foram com objeto perfurante e, destes, as agulhas de injeção foram as mais freqüentes $(52,00 \%)$, sendo que $20,00 \%$ ocorrem com objetos cortantes.

Em vista dos resultados apresentados, concluímos que os trabalhadores de enfermagem estão diante de uma maior exposição ocupacional ao vírus da AIDS e da hepatite B, pela alta freqüência de acidentes com perfurocortantes e reduzida porcentagem de notificações, o que inviabiliza a prevenção com quimioprofilaxia e as possibilidades de monitoramento e acompanhamento sorológico.

Esse estudo indica, portanto, a necessidade de intervenções por parte das instituições, do enfermeiro e dos trabalhadores que contemplem a organização/ reorganização de trabalho, no que diz respeito aos aspectos acima referidos.

\section{REFERÊNCIAS BIBLIOGRÁFICAS}

(1) Zurita IEO, Segurança do trabalho em ambientes hospitalares. Rev CIPA 1993; (4):20-30.

(2) Silva VEF. O desgaste do trabalhador de enfermagem: estudo da relação trabalho de enfermagem e saúde do trabalhador. [tese] São Paulo (SP): Escola de Enfermagem da USP; 1996.

(3) Silva A. Trabalhador de enfermagem na Unidade de Centro de Material e os acidentes de trabalho. [tese] São Paulo(SP):Escola de enfermagem da USP; 1996.

(4) Laurell AC, Noriega M. Processo de produção e saúde: trabalho e desgaste operário. São Paulo: HUCITEC;1989.

(5) Marziale MHP. Estudo da fadiga mental de enfermeiras atuantes em instituição hospitalar com esquema de trabalho em turnos alternantes. [dissertação] Ribeirão Preto (SP):Faculdade de Filosofia de Ciências e Letras da USP; 1990.

(6) Silva VEF. Estudo sobre acidentes de trabalho ocorridos com trabalhadores de enfermagem de um hospital de ensino [dissertação] São Paulo (SP): Escola de Enfermagem da USP; 1988.

(7) Barbosa A. Riscos ocupacionais em hospitais: um desafio aos profissionais da área de saúde ocupacional. [dissertação] Florianópolis (SC): Departamento de Enfermagem da UFSC; 1989.

(8) Gelbcke FL. Processo saúde - doença e processo de trabalho: a visão dos trabalhadores de enfermagem de um hospital escola. [dissertação] Rio de Janeiro (RJ): Universidade Federal do RJ; 1991.

(9) Alexandre NMC. Contribuição ao estudo das cérvicodorsolombalgias em profissionais de enfermagem. [tese] Ribeirão Preto (SP): Escola de Enfermagem de Ribeirão Preto/ USP; 1993.

(10) Marziale MHP. Condições ergonômicas da situação de trabalho, do pessoal da enfermagem, em uma unidade de internação hospitalar. [tese] Ribeirão Preto (SP): Escola de Enfermagem de Ribeirão Preto/USP; 1995. 
(11) Souza M. Conhecimento e aplicação das precauções universais pelos componentes da equipe de enfermagem de um hospital governamental. [dissertação] São Paulo (SP):Escola Paulista de Medicina da UNIFESP;1995.

(12) Benatti MCC. Acidente de trabalho em um hospital universitário: um estudo sobre a ocorrência e os fatores de risco entre trabalhadores de enfermagem. [tese] Ribeirão Preto (SP):Escola de Enfermagem de Ribeirão Preto/USP; 1997.

(13) Brevidelli, MM. Exposição ocupacional ao vírus da AIDS e da hepatite B: análise da influência das crenças em saúde sobre a prática de reencapar agulhas. [dissertação] São Paulo (SP): Escola de Enfermagem da USP;1997.

(14) Coutinho Netto OB. Estudo sobre carga de trabalho e processo de desgaste dos auxiliares de enfermagem de um hospital Universitário de Pernambuco. [dissertação] Rio de Janeiro (RJ): Centro de Pesquisas Aggeu Magalhães do DESC;1998.

(15) Faria LS, Silva VEF. Os riscos fisiológicos e psíquicos identificados entre os trabalhadores de enfermagem em um centro de reabilitação. In: Resumo do 10 Seminário Nacional de Pesquisa em Enfermagem;1999 set., Gramado. Gramado: ABEn; 1999 p.184.

(16) Santos PR. Estudo do Processo de Trabalho da Enfermagem em Hemodinâmica: desgastes, cargas de trabalho e fatores de riscos à saúde do trabalhador. [dissertação] Rio de Janeiro (RJ): Escola Nacional de Saúde Pública; 2001.

(17) Centers for Disease Control US. health-care workers whith documented and possible accupationally acquired HIV infection. MMWR Morb Mortal Wkly 1994; 6(21):

(18) Cole FL. Factors associated with student nurses' intent to provide physical and psychosocial care to persons whit acquired immunodeficiency syndrome. I Prof Nurs 1996;12(4): 217-24.

(19) Abreu AMM, Mauro MYC. Acidentes de trabalho com a equipe de enfermagem no setor de emergência de um Hospital Municipal do Rio de Janeiro. Rev Enferm Anna Nery 2000; 4(1): 139-46.

(20) Jorge R, Poletto M, Almeida AS, Eickhoff CM, Fontana M. Acidentes Biológicos em Hospital Universitário. Rev Med Hosp SVP 2000; 11(26):19-22.

(21) Bulhões I. Riscos do trabalho de enfermagem. Rio de Janeiro: SPC, 1994

(22) Centers For Disease Control Up date: provisional public health services recomenda ions for chemopro-phylasis transmission in health care settings. MMWR Morb Mortal Wkly 1996; 45(22): 468-72.

(23) Cardo DM, Bell DM. Bloodborne pathogen transmission in health care workers: risks and prevention strategies. Infect Dis Clin North Am 1997; 11(2): 331-46.

(24) Einstein HC, Smith DA. Epidemiology of reported sharps injuries in a tertidary care hospital. Hosp Infect 1992; 20(4):271-80.

(25) De Lane S. Risk reduction through testing secreening and infection control precaUnidade de Terapia Intensivaons - with enphasis on needlestick injuries. Infect Control Hosp Epidemiol 1990; 11(10): 563-5.

(26)
Rowe MP, Giuffre M. Evaluating needlestick injuries in nursing personnel. AAOHN 1991; 39(11): 503-7.

(27) Wolff RM, Hidalgo VS. Exposicion accidental del personal de salude a salud a sangre $y$ liquidos biológicos de pacientes. Rev Med Chile1992;120(11):1247-53.

(28) Devries B, Cossart YE. Needlestick injury in medical students. Med J Aust 1994;160(7):398-400.

(29) Shanks NJ, Al-Kalai D. Occupation risk of needlestick injuries among health care personnel in Sandi Arabia. $J$ Hosp Infect 1995; 29(3):221-6.

(30) Souza M, Vianna LAC. Incidência de acidentes de trabalho relacionada com a não utilização das precauções universais na Unidade de Terapia Intensiva. Rev Bras Enferm 1993;46(4):234-44.

(31) Escóssia F. Erros básicos causam acidentes em hospital. Folha de São Paulo. 1998 jun 20; Caderno Cotidiano 3:3.

(32) Siqueira MM, Watanabe FS, Ventola A. Desgaste físico e mental de auxiliares de enfermagem: uma análise sob o enfoque gerencial. Rev Lat Am Enferm 1995; 3(1):45-57.

(33) Marziale MHP, Kourroushi MFC, Robazz, MLCC. Riscos de acidentes no trabalho de enfermagem em Centro Cirúrgico. Rev Enferm UERJ 2000; 8(2):114-20.

(34) Balsamo AC, Barrientos DS, Rossi JCB Acidentes de trabalho com exposição de líquidos corporais humanos ocorridos nos funcionários do Hospital Universitário da Universidade de São Paulo. Rev Med Hosp Univ 2000; 10(1):39-45.

(35) Heiman CG. Cultura, saúde e doença. Porto Alegre: Artes Médicas; 1994.

(36) Douglas JL. Contribuição para a caracterização da enfermagem que atua na assistência da saúde do trabalhador na América Latina. [dissertação] São Paulo(SP): Faculdade de Medicina da USP; 1991.

(37) Seprowitz KA. Ocupationally acquired infections in health care workers. Ann Intern Med 1996; 125(11):917-28.

(38) Sarquis LMM. Acidentes de trabalho com instrumentos perfurocortantes: ocorrência entre os trabalhadores de enfermagem. [dissertação] São Paulo(SP): Escola de Enfermagem da USP; 1999.

(39) Thuler LCS, Vaz LFG Infecção pelo HIV J Bras Med 1994; 66(3):85-108.

\section{Artigo recebido em 18/08/00}

\section{Artigo aprovado em 06/06/02}

